\title{
Transmissão vertical da doença de Chagas em gestantes
}

\author{
Penélope Sant'Ana Leal*, Francisca Neuma de Oliveira**
}

${ }^{*}$ Enfermeira do PSF - Prefeitura de Cotia, ${ }^{* *}$ Enfermeira Obstetra - Prefeitura de SP

\begin{abstract}
Resumo
O presente estudo constitui-se de um referencial bibliográfico pautado no intuito de aprofundar o conhecimento sobre a transmissão da doença de Chagas congênita e investigar como tais alteraçôes podem comprometer o concepto. Descreve pontos importantes com relação às formas de transmissão, notando-se que a transmissão vertical da doença de Chagas é atualmente a via mais importante na sua propagação. Porém, o problema é muitas vezes subestimado, o que torna importante a verificação da existência de alteraçôes fisiológicas na gestante chagásica, relacionada à idade gestacional. Conclui destacando o importante papel do enfermeiro diante desta doença e os instrumentos que as enfermeiras obstetras utilizam para que sejam capazes de intervir nesta realidade em uma perspectiva transformadora.
\end{abstract}

Palavras-chave: doença de Chagas, transmissão vertical de doença, trypanosoma cruzi, fatores de risco, enfermagem.

\section{Abstract \\ Vertical transmission of Chagas disease in pregnant women}

The present study consists of a literature review aiming to intensify knowledge on congenital Chagas' transmission disease and to investigate how such alterations can cause damage to the child. It describes important points with regard to the way of transmission, observing that the vertical transmission of Chagas disease is nowadays the most important way to spread the disease. However, the problem is underestimated, which makes evident that the pregnant with Chagas disease should be examined in order to detect physiological alterations related to gestational age. It was concluded the importance of nurse's role facing this disease and instruments used by obstetric nurses which enable to intervene in this reality with new perspectives.

Key-words: Chagas disease, vertical transmission of disease, trypanosoma cruzi, risk factors, nursing. 


\section{Resumen}

\section{Transmisión vertical de la enfermedad de Chagas en gestantes}

El presente estudio se constituye de una referencia bibliográfica con en el objetivo de profundizar el conocimiento sobre la trasmisión congénita de la enfermedad de Chagas e investigar cómo tales alteraciones pueden comprometer el concepto. Describe puntos importantes con respecto a las formas de transmisión, y se observa que la transmisión vertical de la enfermedad de Chagas es actualmente la vía más importante para su propagación. Sin embargo, el problema es muchas veces subestimado, y se torna importante la verificación de la existencia de alteraciones fisiológicas en la gestante con la enfermedad de Chagas, relacionada a la edad gestacional. Concluye destacando el importante papel del enfermero delante de esta enfermedad y los instrumentos que las enfermeras obstetras utilizan para poder intervenir en esta realidad con una perspectiva transformadora.

Palabras-clave: enfermedad de Chagas, transmisión vertical de enfermedad, trypanosoma cruzi, factores de riesgo, enfermería.

\section{Introdução}

Sabe-se que a partir da década de 80 , a transmissão vetorial da doença de Chagas vem perdendo a sua importância, pois os programas de controle do vetor tornaram-se efetivos e com ampla cobertura, fazendo com que os casos agudos praticamente desaparecessem [1].

No Brasil, entretanto, Pinotti [1] cita que a eliminação do principal vetor e o controle da transmissão transfusional faz com que a via vertical, e entende-se por esta, a via em que a transmissão se dá de mãe para filho, seja considerada como a principal forma de transmissão da infecção chagásica.

Com isso, a transmissão da doença de Chagas em gestantes leva tal gestação a ser considerada de alto risco, apresentando maiores probabilidades de evolução desfavorável tanto para a mãe quanto para o bebê [2].

Daí a importância da realização adequada do pré-natal, através de uma equipe multidisciplinar, em que se devem tomar todas as providências cabíveis, não só com relação aos exames, mas também através das orientaçôes prestadas a estas mães [3].

Já com relação à vacinação, o que Dias [4] menciona é que não há ainda uma vacina específica para prevenir tal doença, porém, muitos cientistas tem se esforçado bastante para desenvolvê-la, contudo, intensificam a orientação de combate ao vetor, na expectativa de controlar ou eliminar a doença em meio rural.

Diniz e Vaz [5] insistem também no que se refere à educação em saúde, de modo a capacitar o indivíduo, levando-o a assumir melhor seu tratamento, evitando complicaçóes desnecessárias, diminuindo seqüelas e melhorando sua inserção social e familiar.
Tal papel é desempenhado principalmente pela enfermagem, conforme cita Alonso [6], mas nada impede que outros profissionais da saúde o façam.

Diante do exposto, a experiência concreta leva-nos a identificar a necessidade de conhecer os determinantes do processo saúde-doença da mulher grávida portadora da doença de Chagas, aprofundar o conhecimento sobre a transmissão congênita, buscando instrumentos teóricos e práticos para que as enfermeiras obstetras sejam capazes de intervir nesta realidade em uma perspectiva transformadora. $\mathrm{E}$, de uma forma mais específica, avaliar a contaminação vertical da doença de Chagas em gestantes chagásicas, correlacionando-as à idade gestacional; investigar como tais alteraçóes podem comprometer o concepto; e, ainda, contribuir como referencial teórico para estudos com o tema em questáo.

\section{Material e método}

Considerando que a presente pesquisa teve o objetivo de analisar e buscar respostas referentes à doença de Chagas congênita, procurou-se através de uma revisão bibliográfica atingir os objetivos propostos.

\section{Resultados e discussão}

\section{A mulher na gravidez}

A reprodução é uma função normal do organismo humano e ainda, uma questáo de relevante importância, devido à tarefa que a sociedade vem impondo à mulher nos últimos trinta anos [7].

$\mathrm{O}$ processo de reprodução humana inicia-se com o encontro em uma das tubas, do óvulo (célula reprodutora feminina), com o espermatozóide (cé- 
lula reprodutora masculina), sendo que o processo reprodutivo envolve atividade sexual, período gestacional, parto, puerpério, amamentação e cuidados com a criança [7].

Pinotti [1] explica que a ausência da menstruação é um sinal de gravidez. Como o ovário continua produzindo o hormônio progesterona, a película interna do útero chamada endométrio, que deveria ser eliminada na menstruação, permanece neste local, desempenhando importante papel no desenvolvimento do embriáo. E ainda, a existência do Hormônio Gonadotrofina Coriônica (HCG) no sangue ou na urina também indica a ocorrência de fertilização.

Observa-se que a gestação é um período em que ocorrem inúmeras modificaçóes fisiológicas adequando o organismo materno às exigências de formação e desenvolvimento fetal, por esta e outras razôes faz-se necessário o acompanhamento da gestante através do atendimento pré-natal [8].

Vale ressaltar que estas alteraçóes podem ser: alteraçôes bioquímicas e metabólicas, alterações hemodinâmicas em que ocorre um aumento do volume plasmático e da freqüência cardíaca, alteraçóes dos sistemas urinário, respiratório e digestivo, além das alteraçóes hematológicas, dermatológicas e ósteo-articular [8].

Assim, a assistência pré-natal visa assegurar que cada gestação culmine no parto de um recémnascido saudável, sem prejuízos à saúde da mãe e em prevenir, identificar e/ou corrigir as anormalidades maternas ou fetais que afetam adversamente a gravidez, incluindo os fatores sócio-econômicos e emocionais, bem como os médicos e/ou obstétricos. $\mathrm{E}$ ainda, instituir a paciente no que diz respeito à gravidez, ao trabalho de parto, ao parto em si, ao atendimento do recém-nascido e aos meios que ela pode valer para melhorar sua saúde [8].

Durante o período gestacional, qualquer problema pode ser duplamente prejudicial, afetando tanto a mãe quanto o bebê. Neste contexto inserese a questão referente ao controle da transmissão congênita da doença de Chagas o que requer adequação no atendimento clínico para a gestante e para o feto [1].

Pinotti [1] revela que muitas mulheres ignoram todas as soluções propostas através da implantação do Sistema Único de Saúde (SUS); e, no caso específico da saúde reprodutiva da população, deixam de lado a posição consolidada no Programa de Assistência Integral à Saúde da Mulher (PAISM).
A intenção deste programa é buscar caminhos para expandir e aprimorar a assistência à saúde das mulheres, de modo a ampliar e melhorar a qualidade do atendimento ginecológico. Além da assistência ao parto, informaçóes sobre o uso de contraceptivos, a prevenção e controle da Aids e doenças sexualmente transmissíveis, o diagnóstico precoce do câncer da mama e do útero, também acompanha questóes polêmicas, como a prática exagerada de cesarianas e o aborto [1].

Assim sendo, é oportuno mencionar que a transmissão vertical da doença de Chagas em gestantes é hoje a via mais importante na propagação da referida doença, sendo que a probabilidade varia entre 0,5 e $8 \%$ e o precário conhecimento sobre a mesma, permite negligência do problema [1].

\section{Gestação de alto risco}

Cerca de $90 \%$ das gestaçóes são normais. Entretanto, aproximadamente $10 \%$ podem náo ter uma evoluçáo satisfatória, por terem características específicas ou por sofrerem algum agravo e, com isso, apresentar maiores probabilidades de evolução desfavorável, tanto para o feto como para a mãe. Esta parcela constitui o grupo chamado de gestantes de alto risco [2].

Uma gravidez de alto risco é aquela em que o risco de doença ou de morte, antes ou depois do parto, é maior do que o habitual, tanto para a máe como para o bebê [9]. Fatores como as condições de saúde da mãe, problemas na gravidez e no feto, por exemplo, sangramentos, incompatibilidade do sistema Rh e má formação e, ainda, acompanhamento ineficiente durante o pré-natal, podem contribuir para a ocorrência de nascimentos prematuros, recém-nascidos com baixo peso e infecçôes. Lembrando que alguns fatores de risco estão presentes antes mesmo de a mulher engravidar, enquanto outros se desenvolvem durante a gravidez [1].

O diagnóstico das mães chagásicas deve ser feito através da realização de pelo menos duas reaçóes sorológicas em caráter de rotina, pelo menos, nos locais onde a freqüência de transmissão congênita é superior a $0,5 \%$ entre as gestantes em geral, como acontece, por exemplo, na Bolívia e no Paraguai [3].

De qualquer forma, as mães chagásicas devem ser detectadas no pré-natal, permitindo que seus filhos possam ser diagnosticados o mais cedo possível e assim possam receber o tratamento adequado [3]. 


\section{Doença de Chagas - retrospectiva histórica}

Do ponto de vista global, a doença de Chagas foi uma das mais completas e bem sucedidas descobertas, pois, um mesmo pesquisador descobriu a doença, seu agente etiológico, o vetor, os reservatórios domésticos e silvestres e os animais de laboratório suscetíveis à infecção [10]. Sua descoberta se deu em 1909, pelo médico brasileiro Carlos Ribeiro Justiniano das Chagas, sendo que, foi vista como problema somente após a década de 60 [3].

Carlos Chagas, assistente do Dr. Oswaldo Cruz - diretor do Instituto Oswaldo Cruz (IOC) -, no Rio de Janeiro, foi designado para controlar a malária entre os trabalhadores de uma estrada de ferro, no norte de Minas Gerais conforme relata Moreno [10]. Além de cuidar dos doentes, Chagas também pesquisava os mosquitos e hábitos dos animais silvestres da regiáo, com isso, encontrou no sangue de um pequeno macaco comum na regiáo um tripanossomo. Estudando os intestinos deste inseto, verificou a presença de inúmeros flagelados da ordem Kinetoplastida, da família Trypanosomatidae, caracterizado pela presença de um flagelo e uma única mitocôndria. Os insetos infectados com os flagelos foram mandados para o IOC, no RJ, ao Dr. Oswaldo Cruz e foram usados para sugar o sangue de macacos de laboratórios, livres de qualquer doença. Três semanas depois, foram verificados tripanossomos no sangue destes macacos [10].

Tal espécie recebeu o nome de Trypanosoma cruzi em homenagem a Oswaldo Cruz. Já o termo doença de Chagas vem de uma homenagem feita ao cientista Carlos Chagas no ano de 1935, ou seja, um ano após sua morte, através de seu filho Evandro Chagas em um congresso na Argentina [10].

Sabendo-se que a distribuição da doença de Chagas é exclusiva do hemisfério Americano, estima-se que em território brasileiro haja de 3 a 5 milhóes de infectados e cerca de 50 mil morrem a cada ano [10].

As áreas endêmicas remanescentes da doença de Chagas no Brasil são as mais pobres e isoladas, com menor produtividade e vivendas mais precárias, particularmente no Nordeste, cujo contexto social e econômico das sub-regióes endêmicas tem permanecido estagnado e em estado de elevada pobreza [4].

É importante ressaltar que em 2001, Minas Gerais recebeu o certificado da OMS/OPAS, de erradicação do Triatoma infestans, vetor da doença, que por ser domiciliado foi o principal responsável pela expansão da endemia. Isso somente foi possível, segundo Andrade [11], devido à implantação de programas de controle do vetor de forma efetiva e abrangente, a partir da década de 80 . Com isso, vem desaparecendo os casos agudos, transmitidos por esta via, em todo o país.

Com a eliminação do principal vetor e o controle da transmissão transfusional, outros mecanismos de transmissão da doença de Chagas são colocados em evidência e, no momento, a via vertical (mãe-filho), no Brasil, passou a ser considerada a principal forma de transmissão da infecção chagásica [11].

\section{Transmissão e diagnóstico da doença de Chagas}

Como vem sendo discutido, a doença de Chagas é uma endemia, ou seja, uma doença infecciosa causada por um parasito que ocorre habitualmente e com incidência significativa em uma dada população. É também chamada de Tripanossomíase americana, uma vez que existe uma outra entidade chamada de Tripanossomíase africana, a doença do Sono [10].

A tripanossomíase americana pode ser transmitida ao homem por via vetorial - contato direto com as fezes do vetor contaminadas com o protozoário, transfusão de sangue e via transplacentária. Outros mecanismos sáo considerados ocasionais: transplantes de órgáos, acidentes de laboratório e via oral [11].

Pode-se fazer uma suspeita se uma pessoa é chagásica, caso ela tenha tido contato com vetores e apresente sintomatologia. Entretanto, para se ter certeza, exames especiais sáo necessários, de acordo com cada fase da doença [4].

A doença de Chagas pode apresentar-se em três formas segundo Dias [4], na fase aguda ou fase inicial, há milhôes de tripanossomos circulando no sangue, o que permite o diagnóstico através de uma gotinha de sangue analisada ao microscópio, podendo-se visualizar diretamente o Trypanosoma cruzi. Forma crônica indeterminada e crônica sintomática ou fase tardia, em que o número de tripanossomos no sangue está muito reduzido e por esta razão, lançam-se máo do método de reaçáo sorológica, em que são realizadas no soro obtido no sangue do doente e verificam-se a presença de partículas que o organismo fabrica contra o Trypanosoma cruzi, denominadas anticorpos. Outras reaçóes como "imonofluorescência" de "hemagluti- 
naçâo" estão hoje muito difundidas e podem ser feitas tanto a partir de sangue tirado da veia, como em pequenas gotas retiradas por picada na ponta do dedo e colhidas em tiras de papel de filtro. Em todas estas formas podem existir parasitos no sangue (parasitemia), o que explica a possibilidade de ocorrer transmissão congênita. Contudo, o maior risco de transmissão da doença é na fase aguda justamente pelo fato de nela a parasitemia ser mais intensa e persistente [3].

A fase aguda, quando aparente, também é caracterizada por uma miocardite que, na maioria das vezes, somente é traduzível eletrocardiograficamente. As manifestaçóes gerais são: febre (pouco elevada), mal-estar geral, cefaléia, astenia, hiporexia, edema, hipertrofia de linfonodos, hepatoesplenomegalia, meningoencefalite (rara) [12].

$\mathrm{Na}$ forma crônica, os sinais clínicos são a hepatoesplenomegalia, presente em todos os casos, icterícia, equimoses e convulsóes decorrentes da hipoglicemia. Náo existe relato de ocorrência de febre [12].

Faz-se importante saber que durante a gravidez ocorre depressão transitória da imunidade, objetivando a náo rejeição do feto, podendo levar, a uma maior suscetibilidade à infecção. Estudos mostram que a grávida coinfectada com HIV apresenta risco aumentado de transmissão congênita do Trypanosoma cruzi, com maior morbidade e mortalidade peri-natal [11].

A doença de Chagas transmitida de mãe para filho através da placenta pode causar abortamentos, prematuridade, natimortos, e ainda levar a uma restrição do crescimento intra-uterino, morte intrauterina, malformaçóes e manifestaçóes clínicas da doença ao nascer [3].

A prevalência da infecção chagásica em gestantes varia de 2 a 51\% em áreas urbanas e de 23 a $81 \%$ nas áreas rurais da América Latina. No Brasil esta prevalência varia entre 0,3 e $33 \%$, sendo que em Minas Gerais, de posse da análise de 18.443 amostras de sangue do Programa de Triagem Neonatal encontraram taxa de $1 \%$ de puérperas chagásicas [11]. O mesmo autor diz:

“... Ao que se refere à taxa de transmissão, no Brasil há uma variação de 1 a $4 \%$ sendo que em Minas Gerais a taxa é de $1,7 \%$. Pode-se estimar que das 240 chagásicas que dão a luz, estejam nascendo de três a quatro crianças com doença de Chagas todo mês.
A infecção congênita pelo T. cruzi é um problema de saúde pública, nos países latinos americanos, pelo menos nos próximos 30 anos, quando se espera que o número de mulheres infectadas em idade fértil deverá reduzir significativamente [11]".

Pelo fato de não existir, atualmente, medidas que evitem a transmissão do parasito da gestante chagásica para seu filho conforme descreve Andrade [11], toda a estratégia de controle da infecção congênita deve ser centrada no diagnóstico precoce da infecção em recém-nascidos de mães infectadas e em tratamento específico imediato das crianças. Os altos índices de cura das crianças tratadas precocemente reforçam a necessidade desta intervenção.

Entretanto, não é aconselhável tratar a mãe chagásica no curso da gestação, a fim de evitar a transmissão congênita, como se faz na toxoplasmose aguda e na infecção sifílica, pois, não se podem monitorizar de forma adequada as possíveis complicaçôes terapêuticas na vida intra-uterina [3].

\section{Profilaxia e tratamento}

Em se tratando de profilaxia, não há um medicamento específico e/ou uma vacina desenvolvida para tal doença [10].

\footnotetext{
"Muito se tem falado sobre uma vacina contra o Trypanosoma cruzi e a doença de Chagas. Muitos cientistas, devotados e de renome, têm dado o melhor de seus esforços para a obtenção de uma vacina eficaz e destituída de efeitos indesejáveis. Alguns têm tido relativo sucesso e têm surgido possibilidades e esperanças. São ainda, entretanto, trabalhos preliminares, necessitando-se de tempo e paciência até que tais vacinas possam ser empregadas na proteçáo do homem. É preciso reconhecer que não se dispóe, hoje, de nenhuma vacina para uso imediato. Por isso mesmo não devem ser diminuídos os trabalhos de combate ao barbeiro, como por exemplo, a melhoria de habitação e o uso de inseticidas, que terminaráo por controlar ou eliminar a transmissão da doença em meio rural [4]".
}

Já com relação ao tratamento, a medicação específica para a doença de Chagas é o Benzonidazol 
sendo este mais efetivo na forma aguda da doença. Nas formas crônicas, o benefício é questionável, devendo-se tratar e acompanhar os sinais e sintomas associados [10].

\section{Qualidade de vida da gestante chagásica e do feto}

A saúde é um completo bem-estar físico, mental e social, e não apenas a ausência de doença. No entanto, existe uma dificuldade envolvendo o conceito de qualidade de vida no que diz respeito ao estabelecimento de padrôes sobre os níveis de saúde, isto significa que além de aspectos objetivos, mensuráveis, deve-se obrigatoriamente incluir aspectos subjetivos que são individuais e mutáveis ao longo da vida de uma mesma pessoa [13].

Teles [14] complementa dizendo que a qualidade de vida pressupóe estar bem com si mesmo e com a vida, ou seja, estar equilibrado, devendo adotar hábitos saudáveis, cuidados com o corpo, atenção para a qualidade dos relacionamentos e tempo para lazer.

Dentro do contexto de uma vida saudável, a gestante de alto risco tem seus direitos aos cuidados especiais garantidos por lei. E deveráo ser concentrados nela, mais esforços sociais, para que a mesma tenha uma boa gestação e um bebê saudável, sem comprometimento de sua saúde [12].

Para o recém-nascido o diagnóstico precoce da infecção por Trypanosoma cruzi é muito importante, uma vez que o tratamento específico, caso seja indicado rapidamente, pode resultar na cura, no melhor prognóstico ou ainda na prevenção do desenvolvimento de seqüelas [3].

\section{Implicaçóes para o concepto}

A doença de Chagas por ser uma doença infecciosa pode causar comprometimento cardíaco, isto é, cardiopatia chagásica. E ainda, comprometer o aparelho digestivo - megaesôfago ou megacólon. Além de outras manifestaçóes clínicas bastante raras, como a meningoencefalite chagásica [1].

As gestantes portadoras de quaisquer tipos de alteraçóes cardiovasculares são consideradas gestantes de alto risco, assim como o concepto, conforme mencionado anteriormente. Por esta razão, a mulher deve ser acompanhada durante o período gestacional por uma equipe multiprofissional, o que inclui pediatra e psicólogo, sendo preciso que estejam todos preparados para eventuais necessidades de exames especializados ou condutas intervencionistas [2].

As possíveis causas de repercussões podem ocorrer devido à cardiopatia materna propriamente dita, o uso de drogas medicamentosas necessárias no controle da cardiopatia, eventual manobra cirúrgica durante o período gestacional, drogas anestésicas usadas durante o procedimento obstétrico, intercorrências cardíacas durante a gestação ou durante o trabalho de parto, ocorrência de efeitos negativos no fluxo uteroplacentário das gestantes cardiopatas que pode levar ao baixo fluxo sanguíneo na circulação placentária dificultando as trocas gasosas do oxigênio e a passagem dos nutrientes para o feto [2].

Em estudo realizado de 1972 a 1991 em que foram analisadas 56.849 gestantes, dessas 15,5\% apresentavam sorologia positiva para Chagas e $1,4 \%$ más formaçóes congênitas. Ao passo que em $84,5 \%$ das não chagásicas houve $3 \%$ com más formaçóes, com isso evidenciou-se náo existir relação entre mães com doença de Chagas e má formação fetal [15].

Contudo, as crianças acometidas de forma congênita podem ser classificadas em assintomáticas e sintomáticas. Quando há sintomas, estes podem ser precoces ou tardios, sendo que, a hepatomegalia é o sinal mais importante do acometimento neonatal da doença, seguido pela esplenomegalia [15].

Outra situação que merece atençáo nestes casos de infecção é com relação ao aleitamento materno. Nas formas aguda e crônica da doença de Chagas, o Trypanosoma cruzi pode ser isolado no leite materno. Há relato de um caso de infecção aguda em lactente de 2 meses de idade amamentado por mãe com a doença conforme mostram Lamounier et al. [16].

Diante disto, experimentos em laboratórios, utilizando amostras de leite humano contaminados com o protozoário e testadas em diferentes condiçôes, demonstraram que a pasteurização do leite previne a transmissão da doença. Além disso, o leite humano aquecido à temperatura de $63^{\circ} \mathrm{C}$ em forno microondas doméstico ( 7 minutos, $45 \%$ potência) mostrou eficiência na redução da transmissão do Trypanosoma cruzi [16].

Entretanto, a raridade da transmissão da doença justifica a manutenção da amamentação em mulheres com a forma crônica, mas se houver sangramento e fissura no mamilo, tal procedimento não deve ser continuado. Nos casos de doença aguda, a nutriz náo deve amamentar seu bebê [16] 


\section{O papel das enfermeiras obstétricas diante da gestante chagásica}

A educação em saúde é hoje um dos meios mais eficazes para o tratamento das doenças crônicas e para prevençáo de suas complicaçóes, pois, amplia a compreensáo que o paciente tem sobre a doença e sobre si mesmo, capacitando-o a assumir melhor seu tratamento e evitando descompensaçôes desnecessárias [5].

É muito freqüente que a mulher apresente transtornos graves em decorrência da doença de Chagas. Neste sentido, o trabalho de educação para gestantes chagásicas, deve ter o objetivo de esclarecer que a melhor forma de lidar com a doença é adquirir o conhecimento dos seus sintomas e das suas complicaçóes, buscando apoio médico e medicamentoso [5].

O cuidado profissional, contextualizado na experiência humana do processo saúde-doença, tem sido um foco disciplinar predominante da enfermagem. Contudo, com relação ao gerenciamento de saúde, cabe ressaltar que qualquer profissional da área em questão, deve estar consciente da importância do seu papel, no que se refere ao esclarecimento e apoio aos pacientes [6].

Com base no exposto, a formação de grupos de apoio é importante pelo fato de se ter um espaço de aprendizagem, de participação e de cidadania onde o indivíduo consegue partilhar interesses, produzir novos afetos e ser acolhido, o que de modo específico é benéfico para as gestantes em questão [17].

As pessoas envolvidas e preocupadas com a doença de Chagas precisam saber quais os avanços e qual postura deve ser adotada diante de tal situaçáo. Em várias regióes o controle da transmissão vem sendo aos poucos priorizado e tem-se alcançado importantes avanços, conforme descrito anteriormente, uma vez que o controle do vetor e a participaçáo dos bancos de sangue em tal prevenção já é uma realidade [4].

Considerando a lei que garante às gestantes de alto risco cuidados especiais, cabe à equipe de enfermagem dispensar-lhe melhores cuidados, paciência, carinho e atenção. Ao hospital, sabendo que é uma empresa que presta serviços à população, cabe promover a satisfaçáo e atender as necessidades destas clientes. Para tanto, é preciso contar com mão-de-obra qualificada, o que requer, dentre vários fatores, treinamento e motivação [4].

Esta conscientização deve incluir ainda a idéia de que os serviços de saúde devem estar voltados para o atendimento das necessidades da população. Ademais, devem ser de qualidade e acessíveis a todos, respeitando o ser humano na sua individualidade e integralidade, como ser social, tornando-se válido repensar e interferir na construção de um modelo assistencial que atenda às necessidades do conjunto da populaçáo [18].

Contudo, o papel da enfermagem é fundamental e sua participação deve ser integral não só neste caso específico, mas também em outras situações [19].

\section{Conclusão}

Pelo que pudemos observar, o problema da doença de Chagas é profundamente sério e alarmante. Náo se trata, somente, de uma moléstia de cura problemática que incide sobre milhóes de pessoas em todas as Américas, mas é também, e muito nitidamente, um retrato da condição humana de grandes massas populacionais, abandonadas aos caprichos da fome e do subdesenvolvimento.

Não bastará nunca, nem à Ciência, nem às necessidades reais destas populaçóes, o combate específico aos vetores ou a simples melhoria das habitaçóes. Há que se fazer conjuntamente, e concretizar, sem demora, uma reformulação imprescindível de mentalidade e de estruturas, visando-se uma promoção integral de todos os homens.

Tâo importante é manter o trabalho que vem sendo realizado pelos bancos de sangue com o intuito de controlar as várias infecçóes que podem ocorrer através deste meio.

Já com relação específica às gestantes chagásicas, percebe-se que depois de instalada a doença, o mais importante é tratar da questão psicológica, uma vez que tal acometimento pode trazer transtornos não só para ela, mas também para o bebê. Além da importância em tratar das complicaçóes que esta doença causa no organismo do indivíduo.

Para isto, a expectativa é de que as drogas e os procedimentos mais necessários para o manejo das principais síndromes clínicas e sintomas venham a evoluir e aumentar o arsenal já disponível, o que em muito contribuirá para o adequado atendimento à gestante chagásica.

Espera-se, contudo, que uma equipe multiprofissional desenvolva da melhor forma possível, o papel que lhe cabe. Ressaltando, sem dúvida, a importância que a enfermagem tem em cumprir bem seu trabalho também educacional diante de situaçóes como estas. 


\section{Referências}

1. Pinotti JA. Saúde da mulher. São Paulo: Contexto; 1998.

2. Ministério da Saúde. Gestação de alto risco. Manual Técnico. Brasília: Ministério da Saúde; 2000.

3. Bittencourt A. Congenital Chagas disease. Am J Dis Child 1976;730:97.

4. Dias JCP. Doença de Chagas no século XXI. 1er Simpósio Virtual de Enfermedad de Chagas [online]; 2008. [citado 2008 Fev 18]. Disponível em URL: http://www. fac.org.ar/fec/chagas/c12pinto/c12pinto.htm

5. Diniz EA, Vaz FAC. Infecçôes congênitas e perinatais. In: Bittencourt AL, Medina-Lopez MD, Camargo ME. Doença de Chagas. São Paulo: Atheneu; 2002. p.17-26.

6. Alonso IK. O cuidado da enfermagem na Saúde da Família: sob o olhar da antropologia da saúde. Revista Técnico-Científica de Enfermagem 2003;1(1):60-5.

7. Berek JS. Tratado de ginecologia. Rio de Janeiro: Guanabara Koogan; 2005.

8. Alencar Junior CA. Assistência pré-natal: manual de orientação. São Paulo: Febrasgo; 2000. 139p.

9. Merck Sharp \& Dohme. Biblioteca Médica online. Problemas de saúde da mulher. [citado 2008 Jul 25]. Disponível em: URL: http://www.manualmerck.net

10. Moreno AMH, Souza ASS, Alvarenga Fo G, Trindade JCB, Roy LO, Brasil PEA, et al. Doença de Chagas [online]. [citado 2008 Jul 27]. Disponível em URL: http://www.ipec.fiocruz.br/pepes/dc/dc.html.

11. Andrade GMQ, Gontijo ED. Diagnóstico e tratamento da Doença de Chagas Congênita. Educação Médica da Faculdade de Medicina da UFMG [online]; 2007. [citado em 2007 Set 15]. Disponível em URL: http:// www.medicina.ufmg.br/edump/ped/chagas.htm

12. Pdamed (Conteúdo em computadores de mão para área médica). Guia digital de doenças infecciosas e parasitárias. [software]. [citado em $2008 \mathrm{Fev}$ 16]. Disponível em URL: http://www.pdamed.com.br

13. Fleck MPA. O instrumento de avaliação de qualidade de vida da Organização Mundial da Saúde (WHOQOL-100): características e perspectivas. Ciênc Saúde Coletiva 2000;5(1):5-18.

14. Teles JM. O que é ter qualidade de vida. Salvador: Real Sociedade Portuguesa de Beneficência Dezesseis de Setembro; 2004.

15. Fragata FOAA, Correia EB, Borges FOR. Seqüência de transmissôes não habituais da infecção chagásica em uma mesma família: transfusional para a mãe e congênita para o filho, de cepa de Trypanosoma cruzi. Revista Soc Bras de Med Tropical 2008;41(1):73-5.

16. Lamounier JA, Moulin ZS, Xavier CC. Recomendaçôes quanto à amamentação na vigência de infecção materna. J Pediatr 2004;80(5):181-8.

17. Bastos AC. O SUS como espaço de aprendizagem. Nursing (Sáo Paulo) 2004;01(1):08-14.

18. Chiavenato I. Introdução à administração. São Paulo: McGraw-Hill do Brasil; 1999.

19. Cianciarullo TI. Compromisso institucional do enfermeiro na área de saúde: a questáo da gestáo do conhecimento. Revista Técnico-Científica de Enfermagem 2003;1(2):101-3. 